Astronomy

\title{
Lights go on all over Europe
}

Astronomers at last week's general assembly of the International Astronomical Union in Manchester expressed concerns about rampant light pollution. High-resolution satellite images reveal the extent of the problem (Cinzano, P. et al. Mon. Not. R. Astron. Soc., in the press). This map of Europe shows the ratios between artificial and natural sky brightness (red is the worst at more than 9:1).

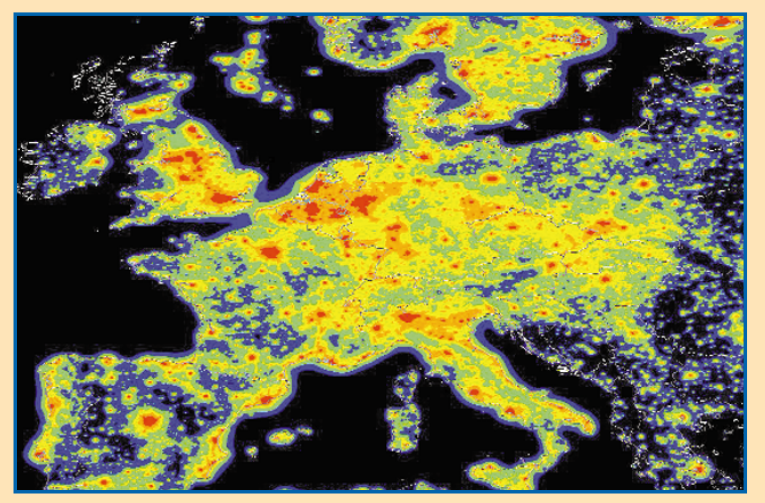

but others saw the reluctance of the elements helium, neon, argon, krypton, xenon and radioactive radon to form chemical bonds as a great challenge to experimental chemistry. They were supported in their quest by theoretical predictions made by the late Nobel prizewinner Linus Pauling ${ }^{2}$, who predicted in 1933 that molecules containing xenon and krypton should exist.

It took nearly 30 years before Pauling's theory was verified by experiment. The breakthrough came in 1962 when Neil Bartlett found that the strongly oxidizing agent platinum hexafluoride, $\mathrm{PtF}_{6}$, is powerful enough to ionize (that is, to remove an electron from) an oxygen molecule, $\mathrm{O}_{2}$, yielding the stable salt compound $\left(\mathrm{O}_{2}\right)^{+}\left(\mathrm{PtF}_{6}\right)^{-}$. Bartlett recognized that the energy needed to remove an electron from xenon is slightly less than the ionization energy of $\mathrm{O}_{2}$, so he carried out the same experiment with xenon and $\mathrm{PtF}_{6}$. The spontaneous reaction produced the first neutral compound to contain a noble gas ${ }^{3}$. Bartlett's discovery was soon followed by syntheses of many other compounds of xenon, and also of krypton, which has only a slightly higher ionization energy than xenon ${ }^{4}$.

This suggests that the ionization energy of the noble gases should be a measure of their willingness to form a chemical bond. The ionization energy, IE, is measured in electron volts, eV. Xenon (IE $=12.13 \mathrm{eV}$ ) compounds are indeed more stable than krypton (IE $=14.00 \mathrm{eV}$ ) compounds. Quantum chemical calculations predicted that neutral compounds of argon ( $\mathrm{IE}=15.76$ $\mathrm{eV}$ ) should also exist, because its ionization energy is still lower than that of fluorine $(\mathrm{IE}=17.42 \mathrm{eV})$. Therefore, salt compounds of $\mathrm{ArF}^{+}$with suitable anions might be stable, although synthesizing them would be a formidable task ${ }^{5}$. Compounds of helium $(\mathrm{IE}=24.59 \mathrm{eV})$ and neon $(\mathrm{IE}=21.56 \mathrm{eV})$ were not expected to be stable because of their very high ionization energies ${ }^{6}$.

Khriachtchev et al. ${ }^{1}$ have now synthesized the first stable neutral argon compound, HArF (Fig. 1). This is an important milestone in the history of chemistry, because the number of elements for which no neutral molecule has been synthesized is now only two. It is also an exciting accomplishment because the strategy used by the authors was different from the one suggested by theory. $\mathrm{HArF}$ is not a salt compound. More exciting is the fact that the type of noble-gas bonding in HArF might also be found in the neon compound $\mathrm{HNeF}$, and even in the helium compound HHeF. In fact, theoretical calculations announced last year predicted that $\mathrm{HHeF}$ could be a stable neutral molecule ${ }^{7}$.

It should be noted that molecules such as HArF are only kinetically stable and exist only in a low-temperature solid matrix (in this case made from inert argon). The molecules rapidly decompose if they come into contact with each other or if they are warmed up, because they break up into unbound argon atoms and HF, which are much more stable species. It is only the energy barrier involved in breaking the weak $\mathrm{H}-\mathrm{ArF}$ bond that prevents it from spontaneous decomposition. So HArF does not fall into the same category as the numerous xenon and krypton compounds, which can easily be prepared and handled in solutions or as solid salt compounds. Nonetheless, the work of Khriachtchev et al. is a further breakthrough in the field of noble-gas chemistry, and might even help chemists to conquer the two least reactive elements, neon and helium. Gernot Frenking is at the Fachbereich Chemie, Philipps-Universität Marburg, Hans-MeerweinStrasse, D-35039 Marburg, Germany. e-mail:frenking@chemie.uni-marburg.de

1. Khriachtchev, L., Pettersson, M., Runeberg, N., Lundell, J. \& Räsänen, M. Nature 406, 874-876 (2000).

Pauling, L. J. Am. Chem. Soc. 55, 1895-1900 (1933).

Bartlett, N. Proc. Chem. Soc. 218 (1962).

4. Laszlo, P. \& Schrobilgen, G. Angew. Chem. Int. Edn Engl. 27, 479-489 (1988).

Frenking, G., Koch, W., Deakyne, C. A., Liebman, J. \& Bartlett, N. J. Am. Chem. Soc. 111, 31-33 (1989).

6. Frenking, G. \& Cremer, D. Structure Bonding 73, 17-95 (1990). Wong, M. W. J. Am. Chem. Soc. 122, 6289-6290 (2000).

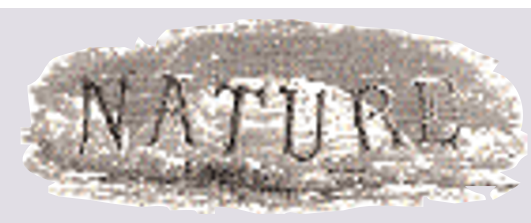

100 YEARS AGO

An interesting and detailed account of Count von Zeppelin's successful trial trip of his navigable balloon on July 2 is given in Die Umschau by an anonymous author, who has endeavoured to dispel the somewhat exaggerated reports which have been circulated as to the success or failure of the experiment. It is pointed out that the delay in the ascent, which some persons attributed to an accident, was really caused by the wind being too strong at the time originally proposed for the trip. The wind-velocity at the time of starting was $\mathbf{5 . 5}$ metres per second, and the balloon was actually driven forwards for a short time in the face of this wind... The wind causing the balloon to drift towards the shore, a descent was made in order that Count Zeppelin might land on the water (to use an Irishism), and thus have his machine towed back by steamer. The descent was very gradual, the cars gently sinking down to the water without the sudden jerk which is commonly experienced in an ordinary balloon.

From Nature 23 August 1900.

\section{YEARS AGO}

If we slide one solid body over another, there is a resistance to the motion which we call friction. What is the cause of this, and what is really happening at the interface between the solids during sliding? It is usually considered that friction is a nuisance, and from the earliest times man has made ingenious attempts to eliminate or to diminish it to as small a value as possible. It is not so much the work we have to do in overcoming the friction-the power losswhich is important, although this can be considerable. In a modern motor-car, for example, about $\mathbf{2 0}$ per cent of the power is wasted in overcoming friction... The real trouble is the damage that is done by the friction-the wear or seizure of some vital part of the machine. It is this factor, perhaps more than any other, which limits the design and which shortens the effective life of, say, an aero-engine or other complex machine. Nevertheless, the credit side is considerable: if the coefficient of friction were much less than it is, walking would be impossible and we should have to use cog wheels or perhaps some system of suction pads like an octopus to get about at all. Conversely, if it were much higher than it is, we should just stick fast wherever we were put.

From Nature 26 August 1950. 